\title{
Polymers and Ceramics Biomaterials in Orthopedics and Dentistry: A Review Article
}

\author{
Tamer M. Hamdy
}

Researcher, Restorative and Dental Materials Research Department, National Research Centre (NRC), Giza, Dokki, 12622, Egypt.

\begin{abstract}
TOWADAYS, strong requirements in biomaterials are still to be met, both in polymers and 1 ceramics substitute, repair and regeneration of hard tissues defects. In this framework, tremendous efforts in the biochemistry especially biomaterials field have greatly impacted the advancement of modern biomedicine. According to development of polymer and ceramics biomaterials utilized in orthopedics and dentistry; there are three different generations, namely first generation which include bioinert materials, second generation which include bioactive and biodegradable materials and recently the third generation (materials that designed to stimulate specific molecular responses). In this review, the evolution of different polymers and ceramics most commonly used in bone regeneration is discussed, highlighting the interesting discoveries in biomaterials tissue engineering applications.
\end{abstract}

Keywords: Orthopedics, Dental, Biochemistry, Biomaterials, Biomimetic, Bioactive, Biodegradation, Bioinert, Bioabsorbable and Bone cement.

\section{Introduction}

Degenerative and inflammatory bone and joint diseases affect a lot of people. Actually, they comprise half of all chronic diseases in people of middle age in the developed countries. Musculoskeletal diseases such as; fractures of bone, low back pain, scoliosis and osteoporosis could be treated using permanent, temporary or biodegradable materials. Thus, the need of orthopedic biomaterials is anticipated to be implanted within the body to perform as natural tissues to restore the affected biological functions by replacing or repairing the damaged tissues such as bone and cartilage.

The first generation of orthopedic biomaterials involved an easily available material, that characterized by being inert as possible in order to avoid their corrosion and leaching out of ions and particles after their implantation in the tissues. The mechanical properties of the implanted materials play a crucial role in the selection of desired materials for manufacturing. Biocompatibility of the synthetic materials is the main concept.

Three different generations could be clearly distinguished: First generation; Bioinert materials, second generation; Bioactive and biodegradable materials and third generation; Bioabsorbable materials which fabricated to stimulate specific cells responses at the molecular level. These three different generations should not be classified as chronological, but conceptual, as each generation denotes an evolution of the requirements and behavior of the biomaterials[1]. The schematic representation of the generations is given in Fig. 1.

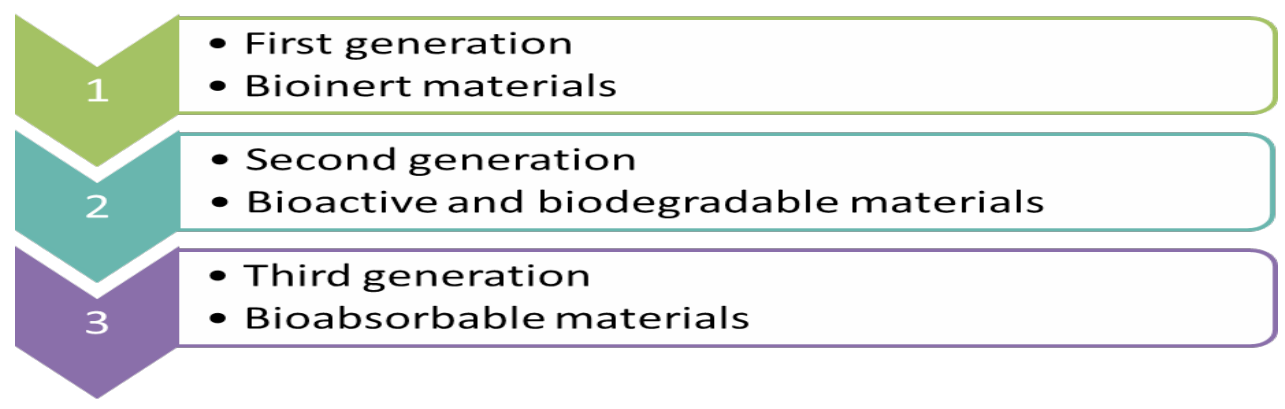

Fig. 1. A schematic representation of the biomaterials generations. 


\section{First generation}

The only requirement of the first use of synthetic materials in biomedical applications was to obtain a suitable combination of mechanical and physical properties to the replaced normal tissue without any toxic response to the host tissues. According to Hench's classification, the first-generation biomaterials characterized by being sufficiently inert to reduce the foreign body reaction and the immune response to be minimal [2].

\section{Polymers}

The most common first generation of polymeric biomaterials are acrylic resins, silicone rubber, polypropylene (PP), polyurethanes and polymethyl-methacrylate (PMMA). Acrylicbased bone cements play an important role in the anchorage of the prosthetic appliance to the surrounding bone tissues in the field of cemented arthroplasties. In 1960, Charnley [3] introduced the auto-polymerized PMMA bone cement for the first time into contemporary orthopedics. The powder phase composed of pre-polymerized PMMA, an initiator (to catalyze the polymerization reaction) and a radiopacifier $\left(\mathrm{BaSO}_{4}\right.$ or $\left.\mathrm{ZrO}_{2}\right)$. The liquid phase consists of MMA monomer, accelerator and stabilizer. Powder and liquid phases are mixed into a paste that after the polymerization process of the monomer it sets and hardens [4].

The PMMA bone cement provides primary fixation of the prosthesis into bone; however it does not provides biological secondary fixation encouragement. Moreover several disadvantages are associated with use of PMMA bone cement such as: residual monomer which may enter the blood circulation producing a embolism, heat generation during setting which may cause necrosis of the neighboring bone, polymerization shrinkage of the cement during setting process which may produces interfacial gaps between the cement and the bone and between the cement and the prosthesis, the difference in the rigidity between the prosthesis and the bone may produce stress that may lead to cracks and leaching out of cement particles which may induce an inflammatory reaction to the surrounding tissues [5].

The addition of the radiopacifier particles decrease the mechanical properties up to $10 \%$ due to the presence of discontinuities that introduced during application of the cement. Thus modern opacifiers based on organic iodine compounds have been introduced [6]. Up till now, acrylic bone cements are still used clinically with a higher successful rate. Vacuum mixing, injecting devices and monomer cooling are significantly improved the cementation procedure and cement mechanical properties. Recently, acrylic-based cements have been widely used in kyphoplasty, vertebroplasty and joint replacement [7].

\section{Ceramic materials}

The most important first-generation nonmetallic inorganic ceramic biomaterials are alumina, zirconia and other porous ceramics. These materials have a restricted range of formulations. The applied manufacturing process includes; firing temperature, porosity, powder purity, grain size and distribution is highly affecting their microstructure and direct role on the mechanical, physical and biological properties. Alumina $\left(\mathrm{Al}_{2} \mathrm{O}_{3}\right.$, Aluminum oxide) is widely accepted in orthopedics for many years due to its low wear and friction. For many years the term ceramic alone without other specification is indication to alumina [8]. Zirconia is considered as one of the highest strength ceramics that referred as steel ceramics which are suitable for orthopedic use. Zirconia demonstrates a highly low wear (less than $0.1 \mathrm{~mm}^{3}$ per million cycles) than alumina inserts for hip prosthetic appliance $[9,10]$.

Highly porous ceramics have been introduced to induce bone tissue growth and to enhance stabilization to the prosthetic appliance. But, the mechanical properties could be compromised in the highly porous materials mainly due to exposer of a large surface to the environment, specially the compression strength [11].

\section{Second generation}

Since 1980 the second generation of biomaterials began to appear, it was defined by the development of bioactive materials. Biomaterials of the second generation have ability to interact with the biological environment to develop a biological response and enhance interfacial bonding. Moreover, the development of bioresorbable materials which have the ability to undergo a progressive degradation at the same time in which a new tissue regeneration and healing will be occurred. Bioactivity could be simply refering to any interaction or effect that biomaterials exert 
on the cells to lead them to specific behaviors and responses. Remineralization and strong bond between the bone tissue and the prosthetic implant is one of the most currently known processes to enhance bioactivity in bone repair and implant fixation $[12,13]$.

Bioactive biomaterials promote bone fixation, repair and enhance regeneration mainly due to precipitation of hydroxyapatite (HA) layers at the material tissue interface. These bioactive biomaterials are widely used in various applications in orthopedic and dentistry, including bioactive glass (BG), ceramic and composites. Though, there are other modifications could be applied to be produced a bioactivity to the materials. These methods include surface treatment with adsorbed proteins and or biomolecules to promote certain cellular responses [14].

\section{Polymers}

Second generation polymers were distinguished by the development of resorbable biomaterials that exhibited a controlled degradation of the polymer chains. Biodegradable polymers include Synthetic and natural polymer such as; polylactide (PLA), polyglycolide (PGA), Polylactic-co-glycolicacid (PGLA), poly ( $\varepsilon$-caprolactone) (PCL), polydioxanone (PDS), polyhydroxybutyrate (PHB), polyorthoester, poly (2-hydroxyethyl- methacrylate) (PHEMA), chitosan, hyaluronic acid and other hydrogels [15]. The bioresorbable materials concept was introduced by Kulkarni et al. in 1960[16]. These polymers have been used for many orthopaedic and dental applications such as bone substitute and repair of bone fractures [17].

Processing of the biodegradable polymers is usually occurred following procedures similar to those of thermoplastics. They can be melted, extruded and molded by compression or injection or solvent cast. The presence of moisture must be carefully considered and controlled because the hydrolytic sensitivity of the polymers leads to a significant reduction in the molecular weight of the materials. Thus, the polymer should completely keep dry before the thermal processing and elimination of any contact with moisture during this time[18].

Many important properties should be considered during designing biodegradable polymers; polymers should be not evoke an inflammatory response; polymer should possess a degradation time coinciding with their required function; polymer should have suitable mechanical properties for their application; polymer should not produce any toxic degradation elements that could be resorbed or excreted; and polymer should be permeable and easily processed [19].

Biodegradable polymers are achieved mainly by the hydrolysis of the polymer backbone and minor extent by enzymatic degradation [20]. The time needed for biodegradation depends on multifactor such as; polymer molecular weight, crystallinity, porosity, concentration of the monomer, geometry, thermal processing and the implant placement. In an aqueous medium, the bulk of the polymer undergoes water penetration, chemical bonds will be attacked and shortening the polymer chains occurred [21].

The most relevant hydrogels of second generation polymers comprise; chitosan, and hyaluronic acid. Hydrogels properties depend on the bonding of hydrophilic macromolecules by strong bonds that form a three-dimensionally network that retain a large water amounts in their internal structure. These types of polymers have been mainly used in tendons, ligaments, cartilage and treatment of intervertebral disc disordered [22].

\section{Ceramic materials}

Ceramic could be classified as; glass ceramics, bioglass $(\mathrm{BG})$ and calcium phosphates $(\mathrm{CaP})$. These materials used as bone substitutes since 1970, mainly as bone cement defect fillers. Their bioactivity is owing to the similarity between bone mineral phase and their structural and surface properties, which enhance binding between ceramics bone without a fibrous tissue formation at the interface[23,24]. Calcium phosphates exist in different forms depending on the manufacturing temperature, impurities and the presence of water. The degree of bioactivity and their degradation behavior generally depends on the calcium to phosphorus $(\mathrm{Ca} / \mathrm{P})$ ratio, crystallinity and phase purity.

The most common $\mathrm{CaP}$ that can be used as $\mathrm{CaP}$ cements are amorphous $\mathrm{CaP}$ (ACP), OCP, TCP, Calcium deficient (CDHA), HA and tetracalcium phosphate (TTCP). These $\mathrm{CaP}$ are injectable, harden inside the damaged bone tissue with least amount of heat generation [26, 29, 30]. Chemical formulae and calcium to phosphorus ratios of the different forms of calcium phosphates are listed in Table 1 [25]. 
TABLE 1. Chemical formulae and calcium to phosphorus ratios of the different forms of calcium phosphates [25].

\begin{tabular}{llc}
\hline \multicolumn{1}{c}{ Forms } & \multicolumn{1}{c}{ Chemical formula } & Ca/P ratio \\
\hline Calcium dihydrogen phosphate monohydrate & $\mathrm{Ca}\left(\mathrm{H}_{2} \mathrm{PO}_{4}\right)_{2} \cdot \mathrm{H}_{2} \mathrm{O}$ & 0.5 \\
Calcium dihydrogen phosphate anhydrous & $\mathrm{Ca}\left(\mathrm{H}_{2} \mathrm{PO}_{4}\right)_{2}$ & 0.5 \\
Calcium hydrogen phosphate dihydrate & $\mathrm{CaHPO}_{4} \cdot 2 \mathrm{H}_{2} \mathrm{O}$ & 1.0 \\
Calcium hydrogen phosphate anhydrous & $\mathrm{CaHPO}_{4}$ & 1.0 \\
Amorphous calcium phosphate (ACP) & $\mathrm{Ca}_{x}\left(\mathrm{PO}_{4}\right)_{y} \cdot \mathrm{n} \mathrm{H}_{2} \mathrm{O}$ & $1.2-2.2$ \\
Octacalcium phosphate $(\mathrm{OCP})$ & $\mathrm{Ca}_{8} \mathrm{H}_{2}\left(\mathrm{PO}_{4}\right)_{6}$ & 1.33 \\
$\alpha$-Tricalcium phosphate $(\alpha-\mathrm{TCP})$ & $\mathrm{Ca}_{3}\left(\mathrm{PO}_{4}\right)_{2}$ & 1.5 \\
$\beta$-Tricalcium phosphate $(\beta-\mathrm{TCP})$ & $\mathrm{Ca}_{3}\left(\mathrm{PO}_{4}\right)_{2}$ & 1.5 \\
Calcium-deficient hydroxyapatite $(\mathrm{CDHA})$ & $\mathrm{Ca}_{10-\mathrm{x}}\left(\mathrm{HPO}_{4}\right)_{\mathrm{x}}\left(\mathrm{PO}_{4}\right)_{6-\mathrm{x}}(\mathrm{OH})_{2-\mathrm{x}}(0<<\mathrm{x})$ & $1.5-1.67$ \\
Hydroxylapatite $(\mathrm{HA})$ & $\mathrm{Ca}_{5}\left(\mathrm{PO}_{4}\right)_{3}(\mathrm{OH})$ & 1.67 \\
Tetracalcium phosphate $(\mathrm{TTCP})$ & $\mathrm{Ca}_{4}\left(\mathrm{PO}_{4}\right)_{2} \mathrm{O}$ & 2.0 \\
\hline
\end{tabular}

Bioactive ceramics have been characterized by being biocompatible and osteoconductive. The most commonly used bioactive ceramics includes; HA: $\mathrm{Ca}_{10}\left(\mathrm{PO}_{4}\right)_{6}(\mathrm{OH})_{2}, \beta$-tricalcium phosphate $\left(\beta\right.$-TCP); $\mathrm{Ca}_{3}\left(\mathrm{PO}_{4}\right)_{2}$ and their derivatives and combinations. According to their synthesis technique, these materials show difference in their physical and chemical properties. HA shows good bioactivity, though its high chemical stability decreases its solubility rate in when compared to other CaP. Actually, after implantation, HA may show high deposition rate upon the bone cement interface as shown in Fig. 2.

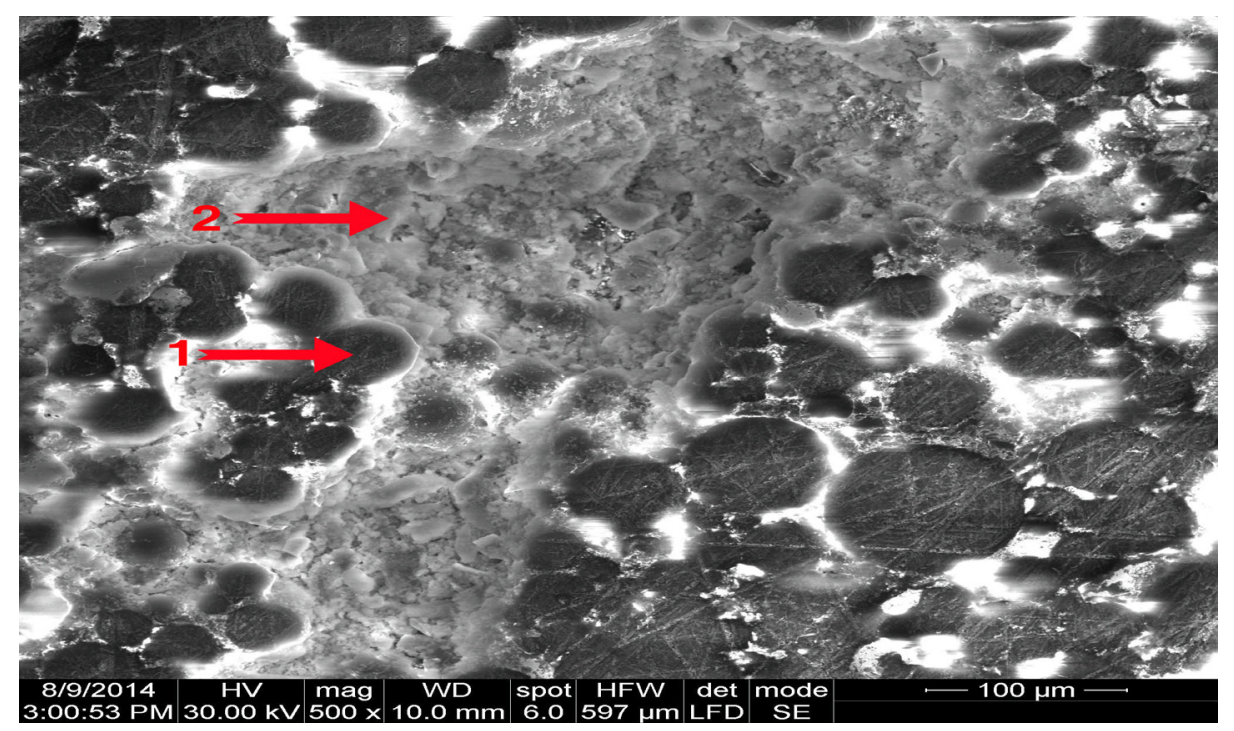

Fig. 2. SEM micrograph, arrow 1 showing CDHA deposition; arrow 2 showing PMMA bone cement.

Hydroxyapatite is a widely used bioactive ceramic since it chemically bonds to bone resulting in a uniquely strong and intimate bone/ implant interface. When bioactive materials contact bone in presence of body fluids, a cascade of events takes place [26] as shown in Fig. 3. These include dissolution of calcium and phosphorus ion, resorption of HA by extracellular and intracellular interactions, precipitation of apatite crystals at the surface of the bioactive material, mineralization of the collagen fibrils and incorporation of the new apatite crystals in the newly formed bone. The precipitated apatite layer on the implant surface forms a biologically active nano-sized layer that firmly bonds to bone. This apatite layer is both chemically and

Egypt.J.Chem. 61, No.4 (2018) 
structurally equivalent to the mineral phase of bone and hence allows interfacial bonding. Once the rate of apatite formation becomes excessively slow, no bond forms and the material become no longer bioactive. Therefore, bioactivity is a timedependent process $[27,28]$.

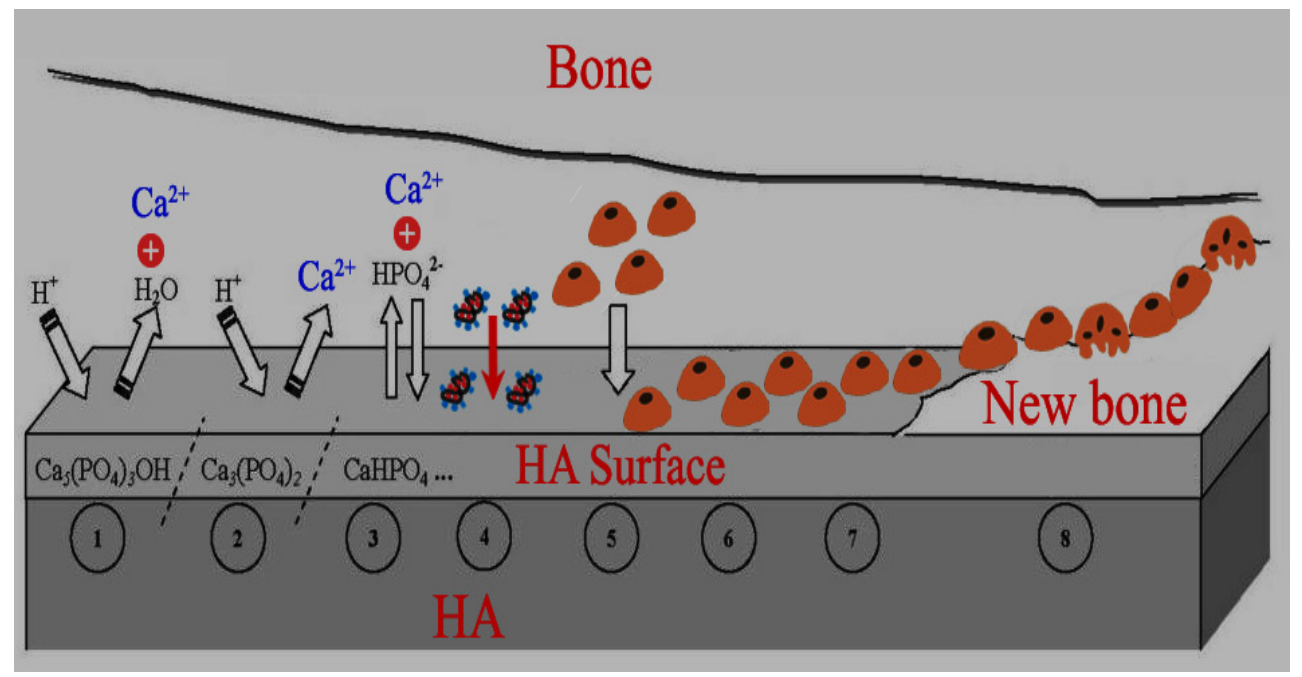

Fig. 3. A schematic diagram representing HA changes after implantation: $(1,2)$ HA dissolution (3) HA composition changes, (4) Adsorption of proteins and or other organic compounds, (5-7) Cell migration, adhesion and proliferation, (8) New bone formation[26].

\section{Third generation}

The third generation novel biomaterials are characterized by being able to produce stimulation to specific cellular responses within the molecular level. The separate concepts of bioactive materials and bioabsorbable materials have changed. The concept of the bioactivity and biodegradability are combined together. Bioactive materials become bioabsorbable and vice versa utilizing nanotechnology to improve their mechanical properties [29].

The properties of the materials should combine to stimulate specific cellular activity and performance. The aim of the third generation biomaterials is to mimic the extracellular matrix (ECM) environment behavior and function. Mainly by developing biomimetic scaffold combined specific cues in its surface. This could be achieved by production of three-dimensional provisional porous that promote cellular behavior including attachment, migration, proliferation and differentiation into a specific lineage. Moreover, surfaces modification with peptide sequences that mimic the ECM components to trigger specific cellular responses are being developed Moreover, cellular behavior control through mechanotransduction and medical and biochemical drugs deliveries are some fields of interest [30].

The development of the third generation biomaterials started nearly at the same time with development of tissue engineering scaffolds applications. Tissue engineering technology offers alternative solutions to conventional tissue transplantation and grafting as allo-grafts, autografts and xeno-grafts which accompanied with severe cellular limitations as donor site necrosis, rejection, possibilities of diseases transfer, in addition to the high cost and post-operative injury. Tissue engineering and regeneration is recent research field dealing with how to build, repair and regenerate tissues by the aid of the natural signaling mechanism and modules such as, growth factors, peptide sequences and stem cells, in combination with natural or synthetic polymers for development of three-dimensional scaffolds for bone, cartilage, ligament, tissue engineering Synthetic biodegradable polymers are successfully used in clinical applications due to their better control of physico-chemical properties. Cellular guidance and stimulation towards a specific response could be effectively achieved through bioactivation of their surfaces via specific biomolecules [19].

In third generation bioceramics, when bioactive $\mathrm{CaP}$ cement used as bone filler for treatment of bony defect there is a rapid regeneration of bone tissues that mimic the normal bone architecture and properties at the repair site. Osteoconduction and osteoproduction occurred in response $\mathrm{CaP}$ 
with release of critical concentrations of soluble ions of $\mathrm{Si}, \mathrm{P}, \mathrm{Ca}$, and $\mathrm{Na}$ from their surface which causes cellular environment responses at the bone cement interface [2,31].

Synthetic bioabsorbable polymers have a great concern due to their ability to be absorbed or eliminated safely, in addition to their improved physico-chemical properties. PHB, PLA, PGA, PCL and their copolymers are the most widely polymers of choice as a third generation. Cells could be seeded into the bioresorbable polymer, then as the cells grow while the biopolymer slowly absorbed at the same rate. Bioabsorbable polymers create sufficient strength with flexibility, while maintaining the structural integrity of tissues until tissues healing [32].

Novel composite scaffolds combining biodegradability and bioactivity privilege exclusive merits in the tissue engineering area. The combination of an inorganic bioceramic phase into a bioabsorbable polymer matrix phase enhance the mechanical behavior of the porous scaffolds, control the degradation process of the polymer and also improves the bioactivity of the scaffolds[33].

\section{Conclusions}

Orthopedic biomaterials research and evolution set up the base for designing and developing an innovative substitute for successful treatment of bone problems. Both first and second generations materials are still effectively used in a wide range of applications modalities. However, the recent third generation biomaterials will open new capability of orthopedics and dental treatments and applications by mimicking the natural tissues repair process.

\section{Conflicts of Interest}

The author declares no conflict of interest.

\section{$\underline{\text { References }}$}

1. Victor S.P., Muthu J., Polymer Ceramic Composite Materials for Orthopedic ApplicationsRelevance and Need for Mechanical Match and Bone Regeneration. J Mechatronics; 2, 1-10 (2014). doi:10.1166/jom.2014.1030.

2. Hench L.L., Polak J.M., Hench L.L., Hench L.L., Splinter R.J., Allen W.C., et al. Third-generation biomedical materials. Science; 295, 1014-7 (2002). doi:10.1126/science.1067404.

3. Charnley J., Anchorage of the Femoral Head Prosthesis to the Shaft of the Femur. Br J Bone Jt Surg; 42-B, 28-30 (1960).

Egypt.J.Chem. 61, No.4 (2018)
4. Mohamed O.A., Elsayed N.H., Haroun A.A., Attia R.Z., Rabie A.M., Microemulsion copolymerization of methyl methacylate and 2-ethyl hexylacrylate as a binder in leather finishing. Egypt J Chem; 59, 759-77 (2016).

5. Vallo C.I., Montemartini P.E., Cuadrado T.R., Effect of Residual Monomer Content on Some Properties of a Poly ( methyl methacrylate ) -Based Bone Cement. J Appl Polym Sci; 69, 136783 (1998).

6. Santos J.G.F., Pita V.J.R.R., Melo P.A., Nele M., Pinto J.C., Production of bone cement composites: Effect of fillers, co-monomer and particles properties. Brazilian J Chem Eng; 28, 229-41 (2011). doi:10.1590/S0104-66322011000200007.

7. Marcucci G., Luisa Brandi M., Kyphoplasty and vertebroplasty in the management of osteoporosis with subsequent vertebral compression fractures. Clin Cases Miner Bone Metab; 7, 51-60 (2010).

8. Gobara H., Synthesis, Mechanisms and Different Applications of Mesoporous Materials Based on Silica and Alumina. Egypt J Chem; 59, 163-94 (2016). doi:10.21608/ejchem.2016.942.

9. Piconi C., Porporati A.A., Bioinert ceramics: Zirconia and alumina. Handb. Bioceram. Biocomposites, p. 59-89 (2016). doi:10.1007/9783-319-12460-5_4.

10. Aboul-Gheit A.K., El-Desouki D.S., Abdel-Hamid S.M., Ghoneim S.A., Ibrahim A.H., Gad F.K., Sulfated zirconia catalysts for low temperature isomerization of n-pentane. Egypt J Chem; 55, 509-27 (2012).

11. Baino F., Novajra G., Vitale-Brovarone C., Bioceramics and Scaffolds: A Winning Combination for Tissue Engineering. Front Bioeng Biotechnol; 3 (2015). doi:10.3389/ fbioe.2015.00202.

12. Tamer M. Hamdy, Application of Nanotechnology in Dental Caries Management. EC Dent Sci; 6, 52-5 (2017).

13. Santin M, Phillips G. History of Biomimetic, Bioactive and Bioresponsive Biomaterials. Biomimetic, Bioresponsive, Bioact. Mater. An Introd. to Integr. Mater. with Tissues, p. 1-34 (2012). doi:10.1002/9781118129906.ch1.

14. Gerhardt L-C., Boccaccini A.R., Bioactive Glass and Glass-Ceramic Scaffolds for Bone Tissue Engineering. Materials (Basel); 3, 3867-910 (2010). doi:10.3390/ma3073867. 
15. El-Gendy A., Abou-Zeid R.E., Salama A., Diab MA, El-Sakhawy M. TEMPO-oxidized cellulose nanofibers/polylactic acid/ $\mathrm{TiO}_{2}$ as antibacterial bionanocomposite for active packaging. Egypt J Chem; 60 (2017). doi:10.21608/ ejchem.2017.1835.1153.

16. Kulkarni R.K., Pani K.C., Neuman C., Leonard F., Polylactic acid for surgical implants. Arch Surg; 93, 839-43 (1966). doi:10.1001/ archsurg.1966.01330050143023.

17. Fonseca A.C., Serra A.C., Coelho J.F.J., Bioabsorbable polymers in cancer therapy: latest developments. EPMA J; 6, 22 (2015). doi:10.1186/ s13167-015-0045-z.

18. Kamaly N., Yameen B., Wu J., Farokhzad O.C., Degradable controlled-release polymers and polymeric nanoparticles: Mechanisms of controlling drug release. Chem Rev; 116, 2602-63 (2016). doi:10.1021/acs.chemrev.5b00346.

19. Manavitehrani I., Fathi A., Badr H., Daly S., Shirazi A.N., Dehghani F., Biomedical Applications of Biodegradable Polymers. Polymers (Basel); 8, 1-32 (2016). doi:10.3390/polym8010020.

20. Tsuji H., Hydrolytic Degradation. Poly(Lactic Acid) Synth. Struct. Prop. Process. Appl., p. 345-81 (2010). doi:10.1002/9780470649848.ch21.

21. Singh B., Sharma N., Mechanistic implications of plastic degradation. Polym Degrad Stab; 93, 561-84 (2008). doi:10.1016/j. polymdegradstab.2007.11.008.

22. Smith L.J., Nerurkar N.L., Choi K-S., Harfe B.D., Elliott D.M., Degeneration and regeneration of the intervertebral disc: lessons from development. Dis Model Mech; 4, 31-41 (2011). doi:10.1242/ dmm.006403.

23. Sadiasa A., Sarkar S.K., Franco R.A., Min Y.K., Lee B.T., Bioactive glass incorporation in calcium phosphate cement-based injectable bone substitute for improved in vitro biocompatibility and in vivo bone regeneration. J Biomater Appl; 28, 739-56 (2014). doi:10.1177/0885328213478256.

24. Eliaz N., Metoki N., Calcium phosphate bioceramics: A review of their history, structure, properties, coating technologies and biomedical applications. Materials (Basel); 10, (2017). doi:10.3390/ma10040334.
25. Dorozhkin S. V., Epple M., Biological and medical significance of calcium phosphates. Angew Chemie - Int Ed; 41, 3130-46 (2002). doi:10.1002/1521$3773(20020902) 41: 17<3130:$ : A ID ANIE3130>3.0.CO;2-1.

26. Dorozhkin S. V., Calcium orthophosphates as bioceramics: state of the art. J Funct Biomater; 1, 22-107 (2010). doi:10.3390/jfb1010022.

27. Nicolazo C., Gautier H., Brandao M-J., Daculsi G., Merle C., Compactibility study of calcium phosphate biomaterials. Biomaterials; 24, 255-62 (2003).

28. Okada M., Matsumoto T., Synthesis and modification of apatite nanoparticles for use in dental and medical applications. Jpn Dent Sci Rev (2015). doi:10.1016/j.jdsr.2015.03.004.

29. Rao S.H., Harini B., Shadamarshan R.P.K., Balagangadharan K., Selvamurugan N., Natural and Synthetic Polymers/Bioceramics/Bioactive Compounds-mediated Cell Signaling in Bone Tissue Engineering. Int J Biol Macromol (2017). doi:10.1016/j.ijbiomac.2017.09.029.

30. Armentano I., Dottori M., Fortunati E., Mattioli S., Kenny J.M., Biodegradable polymer matrix nanocomposites for tissue engineering: A review. Polym. Degrad. Stab., 95, 2126-46 (2010). doi:10.1016/j.polymdegradstab.2010.06.007.

31. Vallet-Regí M., Bioceramics. BioCeramics with Clin. Appl., p. 1-16 (2014). doi:10.1002/9781118406748.ch1.

32. Absdhilash A, Chen JP, Roy K, Donnelly J, Dawkins K, Huibregtse B, et al. Current State of Bioabsorbable Polymer-Coated DrugEluting Stents. Curr Cardiol Rev: [Epub ahead of print] (2016). doi:10.2174/157340 3 X12666161222155230.

33. Navarro M, Ginebra MP, Planell JA, Barrias CC, Barbosa MA. In vitro degradation behavior of a novel bioresorbable composite material based on PLA and a soluble CaP glass. Acta Biomater;1, 411-9 (2005). doi:10.1016/j.actbio.2005.03.004.

(Received 11/3/2018; accepted 21/6/2018) 


\section{البوليمرات والسيراميك الحيوي في جراحة العظام وطب الأسنان: مادة إستعر اض تامر محمد حمدي التحفي قسم العلاج التحفظي و خدو خواص المو اد ـ المركز القومي للبحوث ـ الجيزة ـ مصر.}

تظل هنالك متطلبات قوية في الوقت الحاضر يجب تحقيقها بالنسبة للمواد الحيوية، سواء في البوليمرات

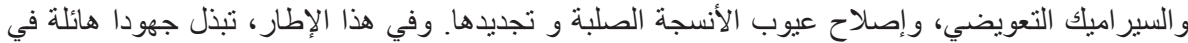

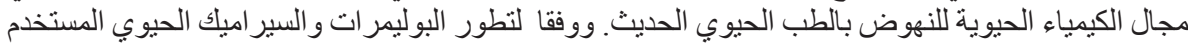

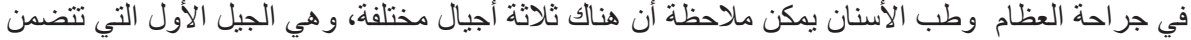

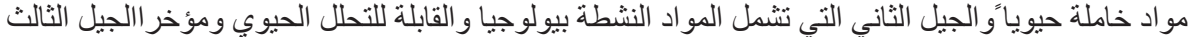

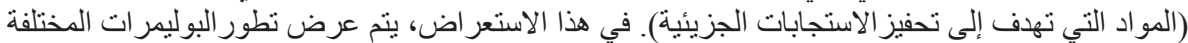

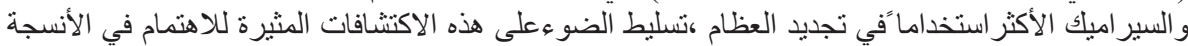
الحيوية وتطبيقاتها. 